\title{
SYMPTOMATOLOGY AND THERAPY OF ANCYLOSTOMIASIS IN LEOPARDS
}

\author{
K. Suresh ${ }^{1}$, P.C. Choudhuri ${ }^{1}$, K. Nalini Kumari ${ }^{1}$, Md. Hafeez ${ }^{2}$ and P.A. Hamza ${ }^{3}$ \\ ${ }^{1}$ Department of Clinical Medicine, College of Veterinary Science, Tirupati, Andhra Pradesh 517502, India. \\ ${ }^{2}$ Professor and University Head, Department of Parasitology and Associate Dean, College of Veterinary Science, Tirupati, \\ Andhra Pradesh 517502, India. \\ ${ }^{3}$ Associate Professor and Head, Department of Epidemiology and Preventive Medicine, Hyderabad, Andhra Pradesh, India.
}

\begin{abstract}
A study of faecal samples of ten Leopards at the Nehru Zoological Park, Hyderabad revealed six of them to be positive for ancyclostome ova. Systematic treatment in the form of administering Ivermectin intramuscularly proved good treatment for the infected animals. This paper reports the diagnosis and treatment of the infection in Leopards.
\end{abstract}

\section{Introduction}

Non domestic felids like Leopards (Panthera pardus) are one of the more popular zoo exhibits. But captivity imposes a significant stress in these animals too, making them susceptible to various parasitic infections resulting in clinical illness. Hence work was taken up to screen the faecal samples of Leopards belonging to Nehru Zoological Park of Hyderabad and to institute treatment in the positive cases.

\section{Methodology}

Faeces from ten Leopards (weighing 30 to $100 \mathrm{~kg}$.) at Nehru Zoological Park was initially screened for helminthic infection by concentration methods and subsequently EPG (eggs per gram of faeces) was calculated on the positive samples by Stoll's dilution method (Stoll, 1923). Clinical symptomatology was recorded in the affected Leopards and were treated with Ivermectin given intramuscularly with the help of blow pipe @ $200 \mu \mathrm{g} / \mathrm{kg}$ body weight. Clinical improvement along with EPG was monitored on days 3 and 7 after therapy and thereafter at weekly intervals for one month.

\section{Results}

Out of the ten Leopards examined, six (5 males and 1 female) were found to be positive for ancylostome ova. The animals

Received on 1 May 2000
Accepted on 1 July 2000 also exhibited symptoms such as dyspepsia, lethargy, mild potbellied appearance, loss of hair (generalised but mild), rough hair coat and passage of blood-tinged slightly loose faeces. EPG in these animals ranged from 500 to 10,900 with a mean value of $4833.3+/-1404.8$. Some improvement in general condition could be noticed three days following treatment, while the consistency of dung had changed to near normal with the disappearance of blood tinge. At this time the EPG ranged between 0 and 350 with a mean value of $166.67+/-47.72$. On the seventh day of treatment the general condition of the Leopards improved markedly. The haircoat became almost normal with a smooth texture. Faeces was also totally normal in appearance and no helminthic ova could be detected.

\section{Discussion}

Based on faecal examination including EPG (4883.3 +/- 1404.8) and clinical symptoms as described previously, the Leopards were diagnosed to be suffering from ancylostomiasis. The clinical symptoms observed were similar to those described by Dakshinkar et al. (1994) in dogs. Ivermectin, a well established efficacious endectocide was used to treat the Leopards. Ramisz (1984) and Bagherwal (1992) reported the efficacy of ivermectin in ancylostome infections in domestic carnivores. Ivermectin acts by inducing tonic paralysis of musculature of many parasitic nematodes by modulating gamma aminobutyric acid mediated neurotransmission (Goodman \& Gilman, 1996). The dose rate of ivermectin used in the present study ( $200 \mu \mathrm{g} / \mathrm{kg}$ body weight) was similar to that used in domestic animals. Fowler (1986) felt that as regards to organophosphorus anthelmintics, dosages recommended for the domestic dog and cat can be used even for non-domestic felids of up to $100 \mathrm{~kg}$. body weight, but the total dosage divided and given on two consecutive days. Ivermectin proved quite efficacious in the present study as evident by a gradual but marked improvement in the clinical symptoms by the seventh day of initiation of treatment as well as faecal examination whose EPG was $166.67+/-47.72$ and 0 (nil) on the third and seventh day respectively following therapy. 
The Leopards continued to be in good health with a completely normal faeces containing no helminthic ova during the period of post therapeutic observation, i.e., upto a month.

\section{Conclusion}

The symptoms of ancylostomiasis in Leopards are similar to those observed in domestic carnivores and Ivermectin can safely be used to treat the infection@200 $\mu \mathrm{g} / \mathrm{kg}$ body weight administered parenterally with the help of a blow pipe.

\section{Acknowledgements}

The authors are grateful to the Director of Nehru Zoological Park for allowing to undertake the work.

\section{References}

Bagherwal, R.K. (1992). Efficacy of Ivermectin against Ancylostoma caninum infection in dogs. Indian Vet. J. 16: 136-138.

Dakshinkar, N.P., Asha Hatwar., S.P. Sharma, V.M. Dhoot and M.D. Kothekar. (1994). Prevalence of gastrointestinal parasites in dogs in Nagpur city. Indian Vet. Med. J. 18: 188-190.

Fowler, M.E. (1986). Zoo and Wild Animal Medicine. $2^{\text {nd }}$ ed. W.B. Saunders Company, Philadelphia, 840 pp.

Goodman and Gilman (1996). The Pharmacological basis of therapeutics. $9^{\text {th }}$ ed. Mc Graw Hill.

Ramisz, A. (1984). Efficacy of ivermectin against endo and ectoparasites in carnivorous animals. Medycyna Weterynaryina, 40: (728-729). Vet. Bull. 4253, 1980.

Stoll, N.R. (1923). Cited by Morgan, B.B and P.A. Hawkins. (1983) Veterinary Helminthology. Burges Publishing Company Minnesota. 